\title{
Musculoskeletal Ultrasound in the Emergency Department
}

\author{
Vito Chianca, $\mathrm{MD}^{1}$ Francesco Di Pietto, $\mathrm{MD}, \mathrm{PhD}^{2}$ \\ Domenico Albano, MD ${ }^{1,4}$ Carmelo Messina, MD ${ }^{1,5}$ \\ ${ }^{1}$ IRCCS Istituto Ortopedico Galeazzi, Milano, Italy \\ 2 Dipartimento di Diagnostica per Immagini, Pineta Grande Hospital, \\ Castel Volturno (CE), Italy \\ ${ }^{3}$ Department of Medicine and Health Sciences, Università del Molise, \\ Campobasso, Italy \\ ${ }^{4}$ Section of Radiological Sciences, Department of Biomedicine, \\ Neurosciences and Advanced Diagnostics, University of Palermo, \\ Palermo, Italy \\ ${ }^{5}$ Dipartimento di Scienze Biomediche per la Salute, Università degli \\ Studi di Milano, Milano, Italy
}

Marcello Zappia, MD, $\mathrm{PhD}^{3}$

Luca Maria Sconfienza, MD, PhD ${ }^{1,5}$

Address for correspondence Vito Chianca, MD, IRCCS Istituto Ortopedico Galeazzi, Via Riccardo Galeazzi 4, 20161 Milano, Italy (e-mail: vitochianca@gmail.com).

Semin Musculoskelet Radiol 2020;24:167-174.

\begin{abstract}
Keywords

- ultrasound

- musculoskeletal

- emergency department

- trauma

- diagnostic imaging

The skin, nerves, and tendons are superficial anatomical structures that can easily be investigated with an ultrasound (US) examination in the emergency department (ED). US evaluation is relatively underused in musculoskeletal evaluation when compared with other emergency applications, such as abdominal trauma, possible aortic aneurysm, and in the cardiovascular system. The aim of this article is to revise the main bone and soft tissue conditions that can be assessed using US in the ED.
\end{abstract}

Musculoskeletal (MSK) and soft tissue conditions represent a high percentage of admissions to the emergency department (ED). Ultrasound (US) evaluation of these conditions has become increasingly more prevalent in recent years. ${ }^{1}$ The role of MSK US in the emergency setting continues to improve; it is useful for both early diagnosis and interventional procedures, for example in cases of abscess or hematoma. $^{2}$

The main advantage of emergency MSK US is the rapid evaluation of symptoms at the bedside with both static and dynamic assessment that can be useful for the diagnosis of pathologies relating to skin and subcutaneous tissues (abscesses, cellulitis, hematomas), muscles, ligaments and tendons (tears and strain), bone (fractures), and nerves (avulsion, traumatic tears).

This article reviews both the common and uncommon MSK pathologies focusing on the main findings that might influence medical decision making regarding the patient in the ED.

\section{Skin and Subcutaneous Tissues}

Skin and soft tissue infections (STIs) such as abscess and cellulitis are frequently encountered in the ED. Staphylococcus aureus and Streptococcus species cause most of these infections, although other pathogens are occasionally involved. ${ }^{3}$ Growing scientific evidence indicates that US increases diagnostic accuracy in skin and STIs and can influence patient management. ${ }^{4}$ It may show signs and findings of inflammation such as fluid collections, edema, and soft tissue (ST) stranding. ${ }^{2}$

Cellulitis, the most common type of STI, is confined within the subcutaneous compartment. It is a clinical diagnosis, and patients may present fever and leukocytosis in addition to painful and swollen erythema in the affected area. ${ }^{5}$ The US findings of cellulitis are nonspecific; edema and inflammation in the skin and ST is responsible for the alterations on US. The most common finding is the "cobblestoning" appearance that corresponds to fluid-filled areas that separate the ST and fat in
Issue Theme Musculoskeletal Ultrasound Update; Guest Editor, Alberto Stefano Tagliafico, MD
Copyright $(2020$ by Thieme Medical Publishers, Inc., 333 Seventh Avenue, New York, NY 10001, USA. Tel: +1(212) 760-0888.
DOI https://doi.org/ 10.1055/s-0039-3402050. ISSN 1089-7860. 
a stripy morphology; other nonspecific appearances include swelling and increased echogenicity of the skin and ST. Color or power Doppler tools show hyperemia of the infected areas. ${ }^{6}$

Necrotizing fasciitis is an uncommon, severe form of cellulitis characterized by a rapid clinical deterioration with significant morbidity and mortality. ${ }^{7}$ The early stage of necrotizing fasciitis is clinically indistinguishable from STIs such as cellulitis and erysipelas, making an early diagnosis challenging. Necrosis may be caused by microcirculation thrombosis with consequent ischemia. ${ }^{8}$ The US examination shows subcutaneous thickening with perifascial hypoechoic fluid collection and air where necrotizing fasciitis is concerned.

Abscess is a muscular or subcutaneous collection of necrotic and infective tissue with bacteria, inflammatory exudate, and polymorphs. ${ }^{9}$ Usually abscesses present roundshaped morphology, although they may also be geographic or irregular. US findings depend on the maturity of the collection, and their echogenicity can vary from hypoechoic to isoechoic or hyperechoic with an irregular wall thickness and typical posterior acoustic reflection. Internal debris is common, and gas may be seen in case of anaerobic bacteria such as Clostridium perfringens. Color or power Doppler imaging shows variable grades of hyperemia of the abscess wall and the surrounding tissues. ${ }^{6}$

Hematoma is a blood collection located in ST or muscles; it occurs as a result of trauma, especially in patients who have received anticoagulant treatment. ${ }^{10}$ US appearance of a hematoma varies with its timing; hyperacute and acute hematomas (until a few days old) appear as an anechoic or slightly hypoechoic lesion with increased enhancement of the echoes behind the lesion, indicating the presence of liquid blood. Subacute hematomas become more complex (with methemoglobin presence), indicating blood clot formation (-Fig. 1). Chronic hematomas may also present a solid structure with different echogenicity due to the different products of hemoglobin (ferritin and hemosiderin) and calcification or become anechoic again (sign of liquefication). ${ }^{11}$

Less commonly, ligament strain or tears can also cause hematoma formation due to blood extravasation near the ligament structures (-Fig. 2). Any hematoma with nodular

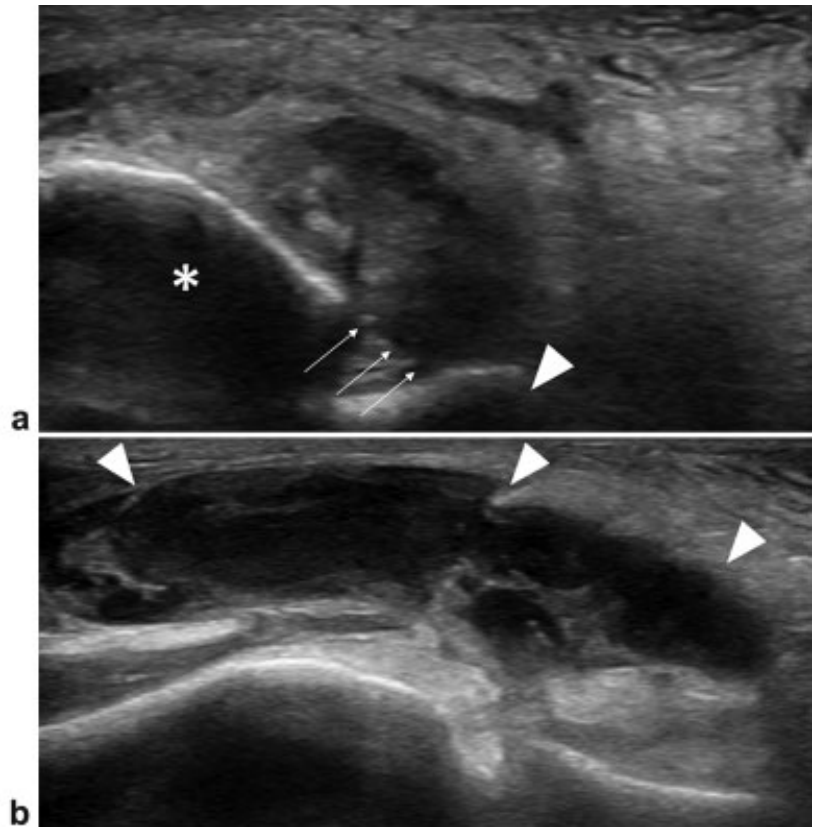

Fig. 2 (a) US images of ruptured anterior talofibular ligament (arrows) with smooth and undefined ligaments ends at fibular (asterisk) and talar (arrowhead) surfaces. (b) Bulky inhomogeneous hematoma (arrowheads) with fibrin debris near the torn ligament.

areas should be followed until its resolution to exclude an underlying tumor, especially if no significant traumatic event has occurred. ${ }^{10}$

A particular form of subcutaneous fluid collection is represented by the Morel-Lavallée lesion, a seroma caused by the separation of the subcutaneous tissue from the underlying muscular fascia. ${ }^{12}$ It mostly occurs on the lateral side of the thigh around the greater trochanter, typically after shear trauma during motorbike accidents. ${ }^{12}$ In these cases, US shows the presence of a hypo/anechoic collection confined to the subcutaneous tissue, never breaching the muscular fascia, occasionally with some floating hyperechoic fat lobules. It is not uncommon for this lesion to measure $>20 \mathrm{~cm}$ in length.

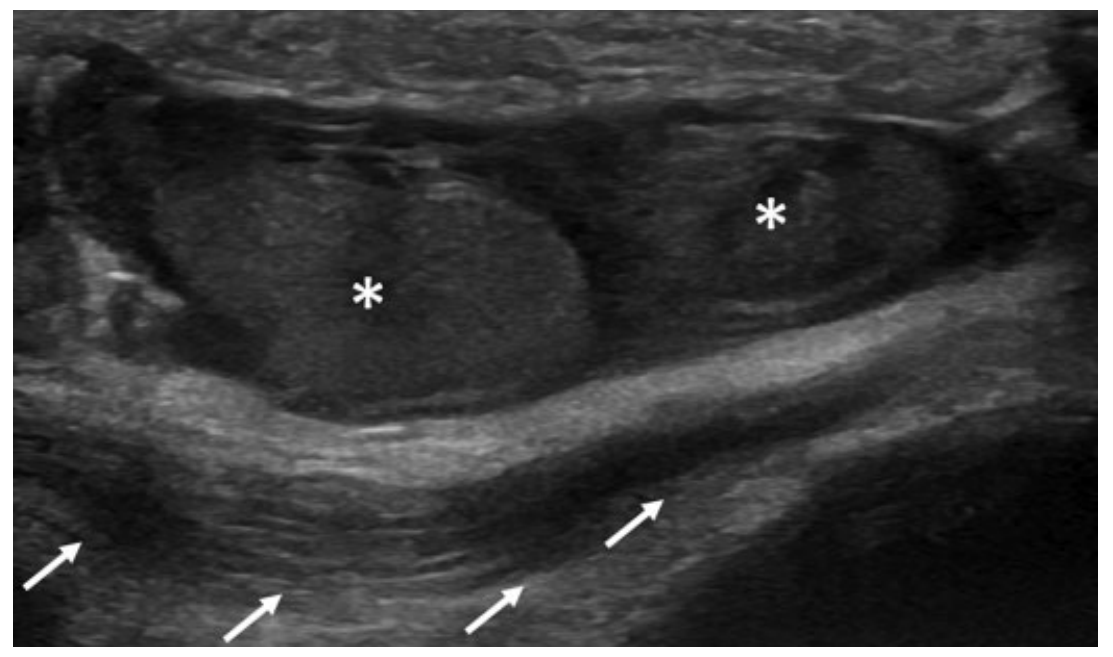

Fig. 1 Subacute soft tissue hematoma of the knee (asterisks) that determines posterior dislocation of the patellar tendon (arrows). 
Overall, US may serve as a useful method to guide percutaneous aspiration in most of these conditions. ${ }^{13-17}$

\section{Foreign Bodies}

Penetrating injuries with retained foreign bodies are one of the most frequent reasons for ED admission. In the literature, a rate of $38 \%$ of retained bodies overlooked at initial clinical and radiologic examinations was reported. ${ }^{18}$ The most common retained foreign bodies are metal, glass, or wood/plant splinters. Their detection is important because retained foreign bodies may lead to inflammatory or infective complications. ${ }^{19}$ Radiographs are able to depict $\sim 80 \%$ of all foreign bodies, but radiolucent types remain undetected, so US evaluation is imperative. ${ }^{20}$

Several studies reported that US offers sensitivity ranging between $87 \%$ and $94 \%$ and specificity of 97 to $99 \%$ in the detection of foreign bodies. ${ }^{20-22}$ The degree of echogenicity of the foreign bodies is due to the acoustic impedance at the interface between them and surrounding tissue. Smooth surfaces produce reverberation artifacts, whereas bodies with irregular or curvilinear margins produce clean shadowing. Metal and glass, in particular, if imaged perpendicular to the US beam, produce reverberation due to their flat surfaces (-Fig. 3). ${ }^{23}$ Inflammatory reactions produce a typical hypoechoic rim around the foreign bodies if present in the ST $>24$ hours. However, false positive results can be caused by calcification, scar tissue, or air trapped in the ST, and so correlation with radiographs is always recommended. ${ }^{24}$

\section{Fracture}

US was described as accurate for bone fracture diagnosis, and the carpal bones are one of the major anatomical sites investigated with US (-Fig. 4). ${ }^{25}$ Many articles describe the utility of US for early detection of scaphoid fracture (-Fig. 5) with a sensitivity ranging between $86 \%$ and $100 \%$ and a specificity of and 95 to $100 \%{ }^{26,27}$ Radiographs show lower sensitivity (37\%) and specificity (40\%). ${ }^{28}$ The ribs are another crucial anatomical site that could be investigated with US (-Fig. 6); in particular, rib fracture is a challenging diagnosis with radiographs with a sensitivity of $41 \%$ and a specificity of $100 \%$, whereas articles report high sensitivity ranging between $78 \%$ and $98 \%$ and a specificity of $100 \%$ for US in cases of chondral rib fracture. ${ }^{29,30}$ The principle for fracture diagnosis is to apply the transducers on the most painful regions. The typical finding for a fracture diagnosis is the interruption of the hyperechoic cortical line; hematoma and ST swelling can also be observed as indirect evidence near the fracture.

Emergency US examination may also be used for the evaluation of hemarthrosis, a frequent finding in intra-articular injuries, and for the assessment of fracture reduction. ${ }^{31}$

An unusual use of US is bone realignment, in particular for pediatric fractures. It was demonstrated that bedside USguided reduction of closed pediatric forearm fractures is safe and effective. ${ }^{32}$ With this tool the clinician has real-time visualization of the entity of bone reduction with lower sedation and fewer operative attempts.
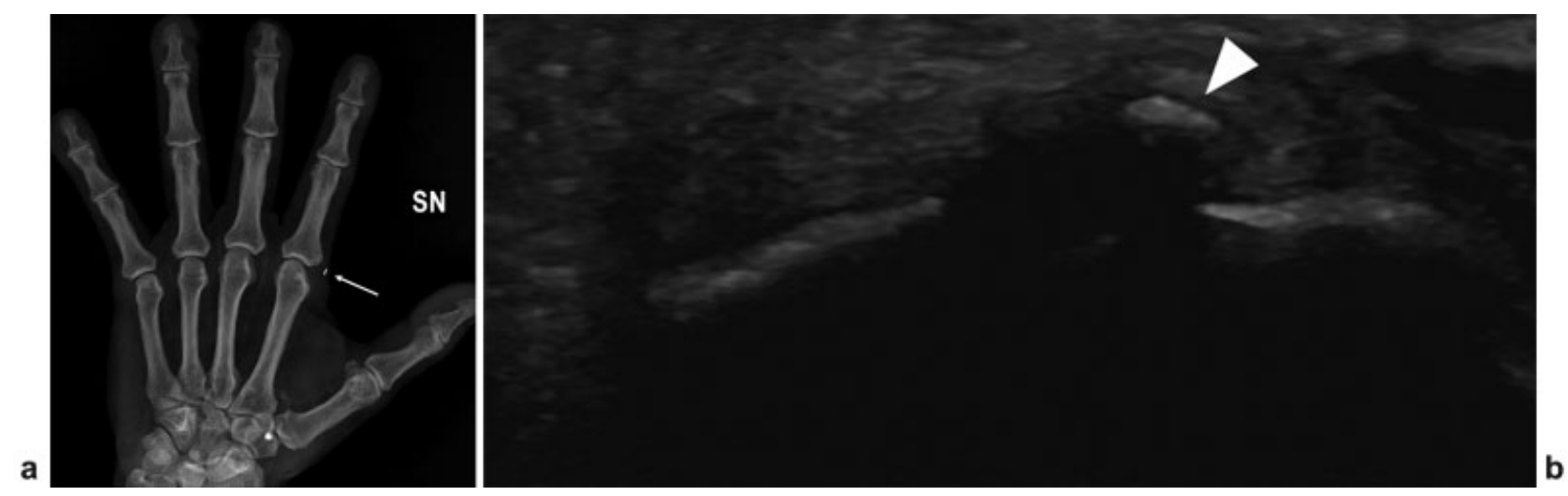

Fig. 3 (a) Radiographic film shows a metallic foreign body (arrow) into the soft tissue at the second metacarpophalangeal joint that is better depicted with (b) an US examination (arrowhead).
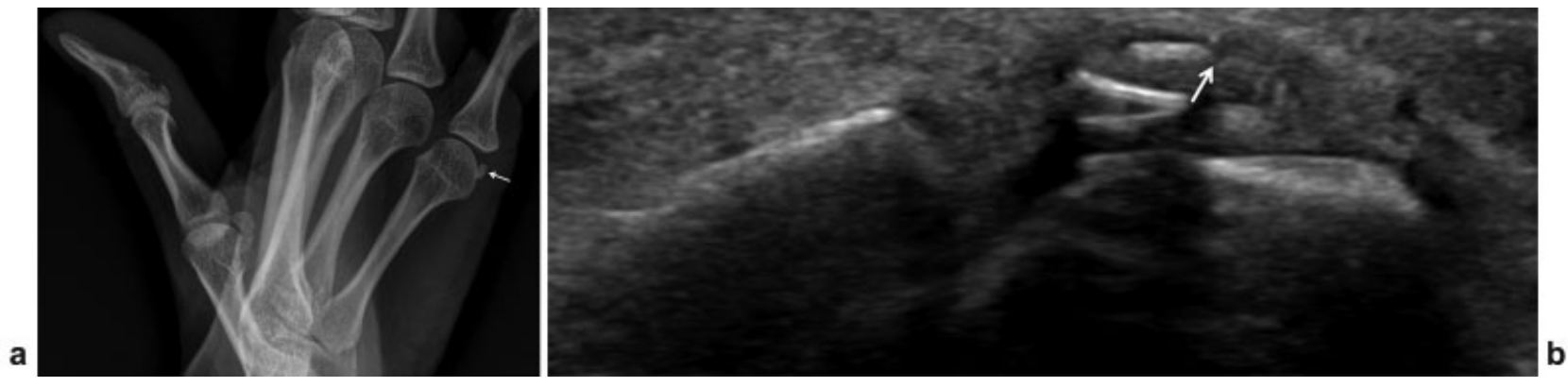

Fig. 4 (a) Oblique radiographic view shows a doubt radiolucency into the sesamoid bone of the fifth metacarpophalangeal joint (arrow). (b) US image shows a fracture rim of the sesamoid bone (arrow). 

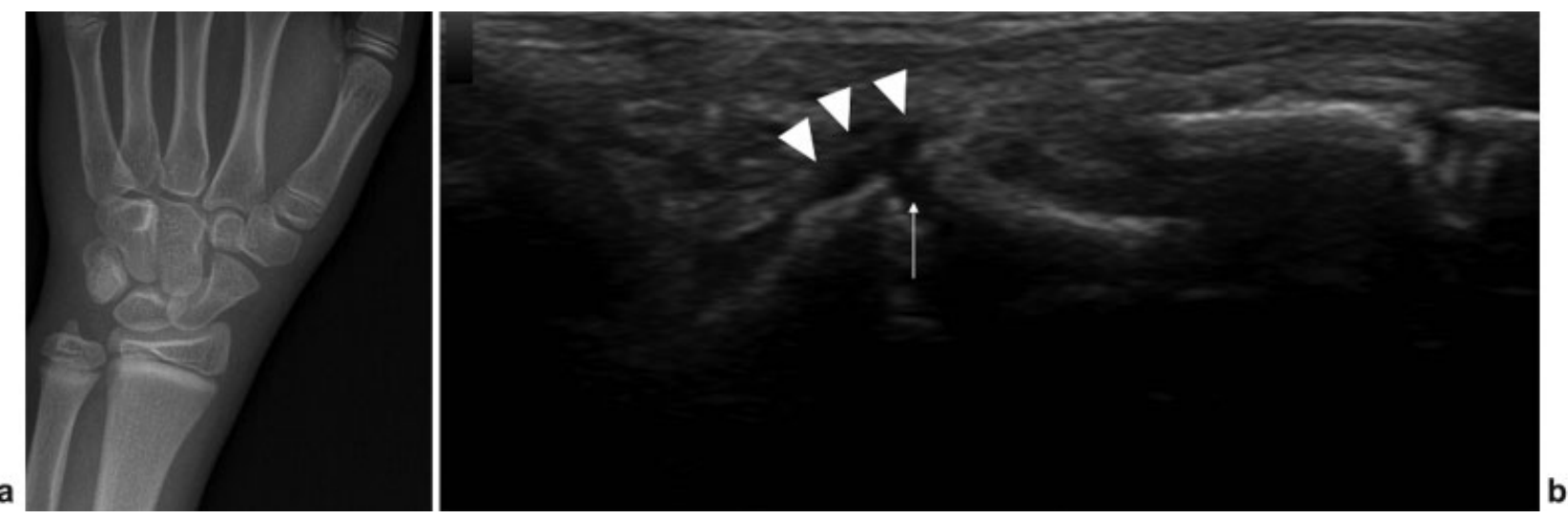

Fig. 5 Scaphoid fracture. (a) Radiography shows trabecular crowding at the distal pole of the scapoid (arrow). (b) US shows a scaphoid fracture with cortical discontinuity (white arrow) and periosteal hematoma (arrowheads).
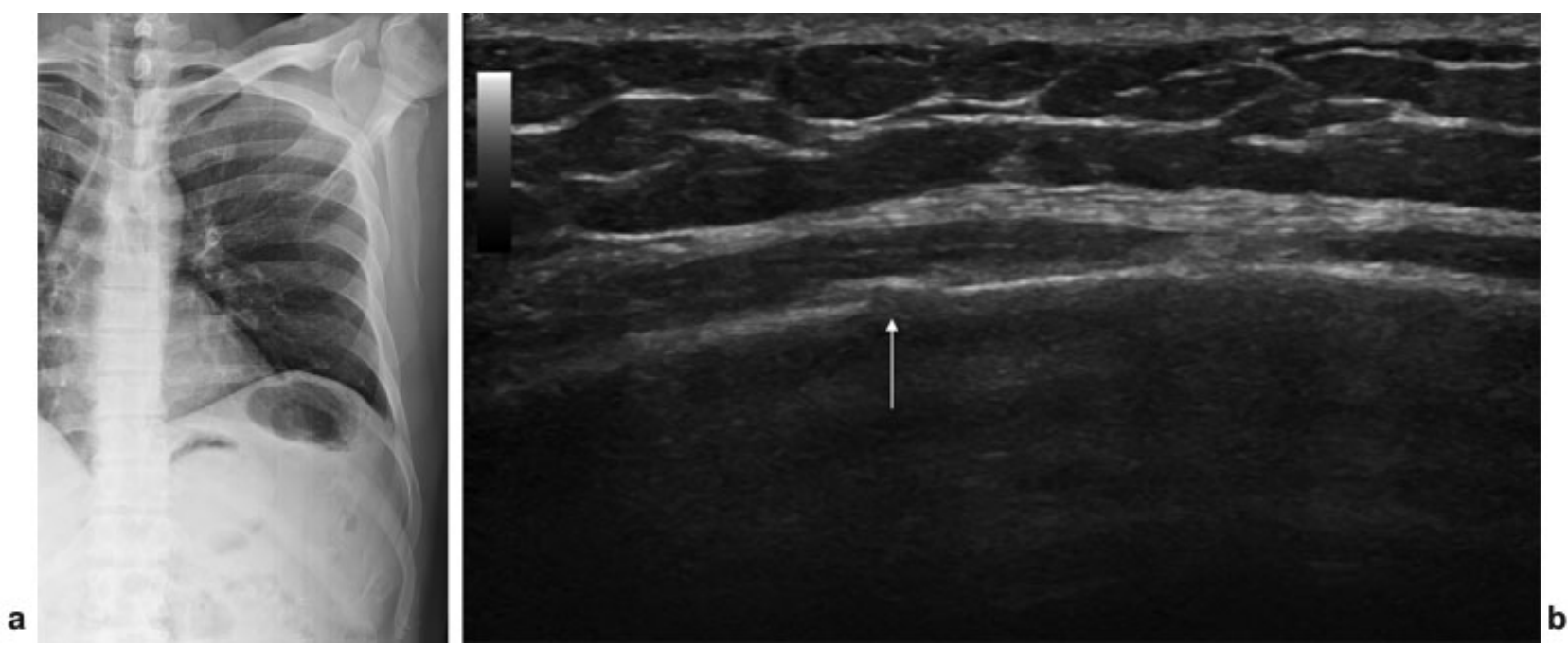

Fig. 6 (a) Chest radiography performed for pain arisen after intense cough. The film is unremarkable. (b) US evaluation shows a tiny infraction of the seventh rib (arrow).

\section{Muscle and Tendon Injury}

Muscle and tendon injury are common events in patients admitted to the ED. In general, tendons with normal underlying matrix do not tear unless very high forces are applied. In most cases, the myotendinous junction is the preferential site for tearing. The cause of tendon rupture is variable and ranges from trauma over a degenerated tendon to a penetrating laceration. Full-thickness tears are considered when complete discontinuity of the tendon is noted with a fluid-gap area ( - Fig. 7) that becomes more visible on dynamic evaluation. ${ }^{33,34}$ The Achilles, patellar, quadriceps, and distal biceps are the most common tendons presenting with a full-thickness tear in the ED. ${ }^{35,36} \mathrm{~A}$ partial-thickness tear is diagnosed when alteration in tendon diameter is seen with different degrees of detachment of the tendon bundles. ${ }^{37,38}$

In almost all cases of tendon full-thickness tears, surgical treatment is required. According to the involved tendon structure, it is useful to evaluate the presence of anatomical variations of the neighboring nerve structures or to report specific findings. As an example, in the case of Achilles tendon rupture, the evaluation of anatomical variation such as a reduced distance between the sural nerve and the injured tendon may be useful in preoperative planning before a percutaneous approach. ${ }^{39}$ Also, it is important to report the presence and integrity of the plantaris gracilis tendon, a thin accessory tendon running on the medial side of the Achilles tendon, that can occasionally be used as a graft for tendon repair.

Muscle injuries are another frequent cause of admission in the ED and can be classified as extrinsic or intrinsic lesions. ${ }^{40}$ Extrinsic muscle injuries are due to a nonpenetrating injury that causes contusion of the muscle belly against the underlying bone. For this reason, these lesions frequently affect deep muscles, such as the vastus intermedius. These injuries occur frequently in athletes who practice contact sports. The contusion produces a tear of muscle fibers and blood vessels that result in hematoma and myofiber necrosis. ${ }^{41}$ US appearance of extrinsic injuries depends on the extension and on timing between the injury and the examination. In mild contusions, US shows inhomogeneous isoechoic muscle swelling in comparison with the surrounding undamaged muscle tissue. In 


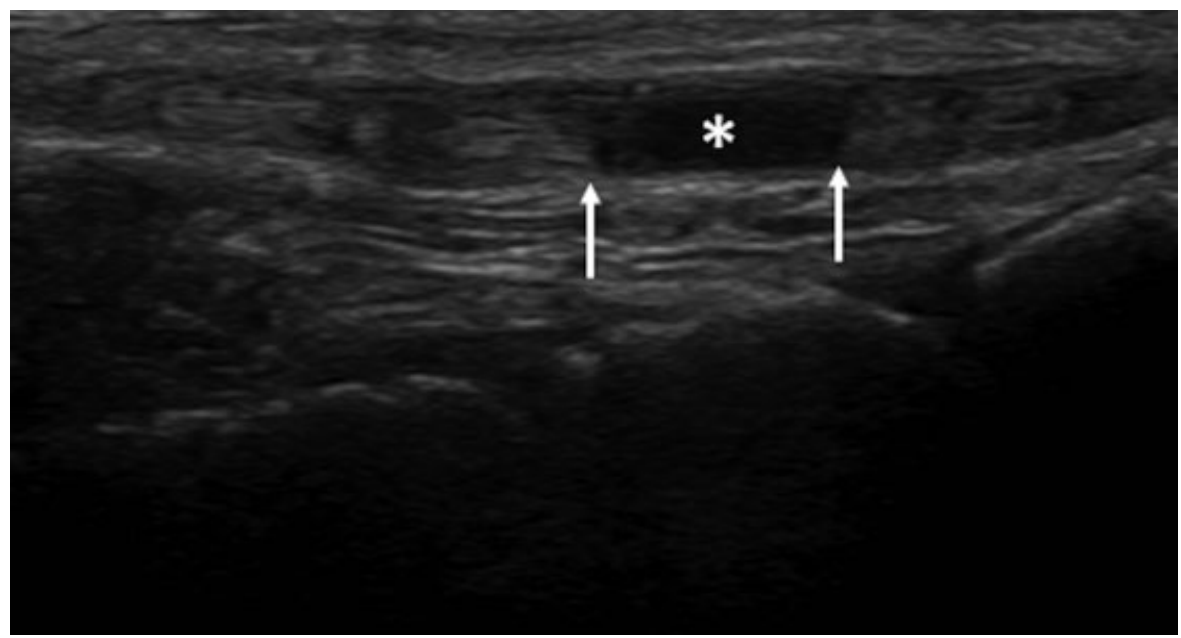

Fig. 7 Extensor hallucis longus tendon tear after cut injury. US shows detached tendon stumps (arrows) and interposed fluid gap (asterisk).

severe contusions, hematomas usually fill the gap of the torn muscle (-Fig. 8).

Intrinsic muscle lesions are related to muscle strain during the eccentric phase in which the force of active contraction is added to the stretching force applied to the myotendinous junction. ${ }^{42,43}$ Several classifications are available categorizing intrinsic muscle injuries; however, there is no universally accepted classification system. The most used classification divides muscle strains into three grades on the basis of US appearance: mild, moderate, and severe. ${ }^{44}$ US evaluation of mild injuries (grade 1) may be negative or exhibit ill-defined areas of increased echogenicity or fiber disruption occupying $<5 \%$ of the cross-sectional area of the muscle. Moderate injuries (grade 2 ) involve $>5 \%$ of the crosssectional area, and US often shows fiber disruption and discontinuity of the perimysium at the myotendinous junctions. ${ }^{44,45}$ In severe injuries (grade 3 ), a complete rupture of the muscle fibers with associated hematoma is seen. Grade 3 lesions are usually clinically evident with a palpable gap between the retracted stumps of the affected muscles. Perifascial fluid detection is an unspecific finding because it can occur in any grade of muscle strain. ${ }^{42}$
Muscle herniation is another unusual cause of ED admission, usually seen after local blunt trauma. ${ }^{46}$ It refers to the herniation of some muscle fibers through a defect in the deep fascial muscles layer. In those cases, a palpable mass may be detected that usually increases when the affected muscle is contracted or the patient is standing erect. ${ }^{47}$ Dynamic US evaluation is able to detect muscle bulge through the fascial defect on muscle contraction and reduction on relaxation ${ }^{48}$ (-Fig. 9).

\section{Calcific Tendinopathy}

Calcific tendinopathy is a common condition mainly affecting the rotator cuff tendons of women $<50$ years of age. ${ }^{49}$ Depending on the stage, calcific tendinopathy can be totally asymptomatic, present with chronic mild pain, or generate an unbearable pain usually nonresponsive to common oral painkillers. ${ }^{50}$ In this last condition, patients generally present to the ED seeking care. In general, the clinical diagnosis is straightforward, based on patient symptoms. In most cases, a shoulder radiograph is performed that may show the presence of a subacromial radiopaque calcific deposit. ${ }^{51}$ However, in some
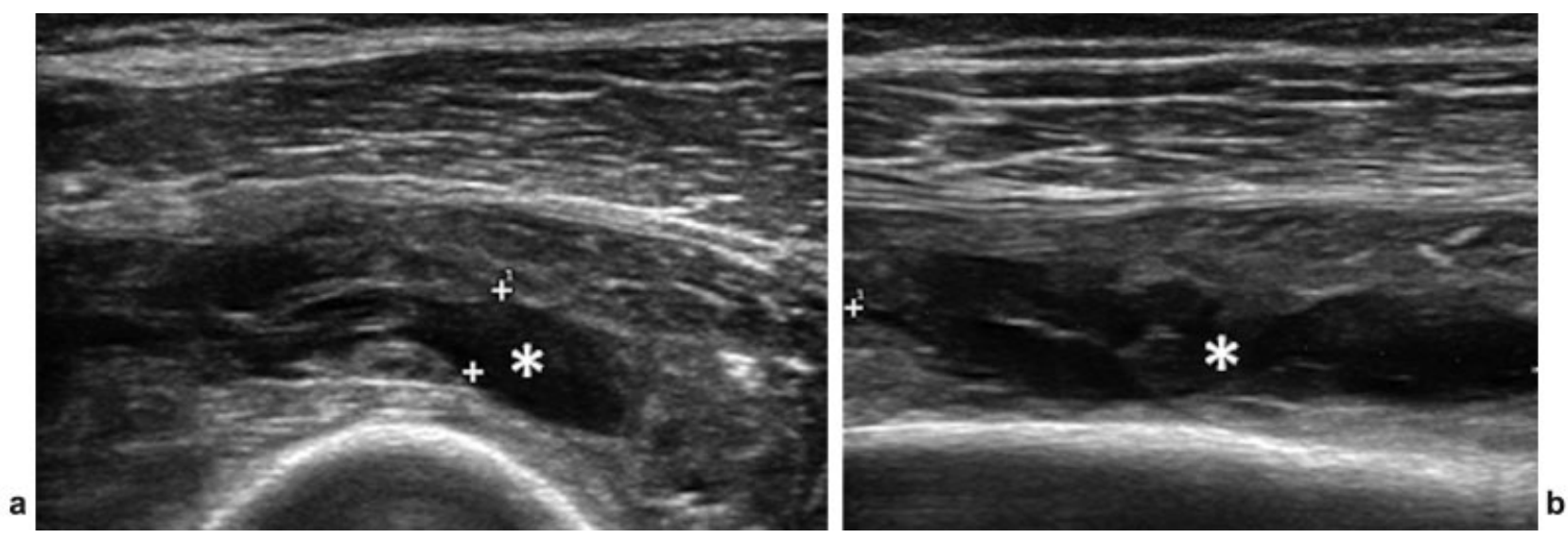

Fig. 8 Intramuscular hematoma of the vastus intermedius. (a) Short and (b) long axis US evaluation show an intramuscular inhomogeneous mass (asterisk) after direct trauma. 

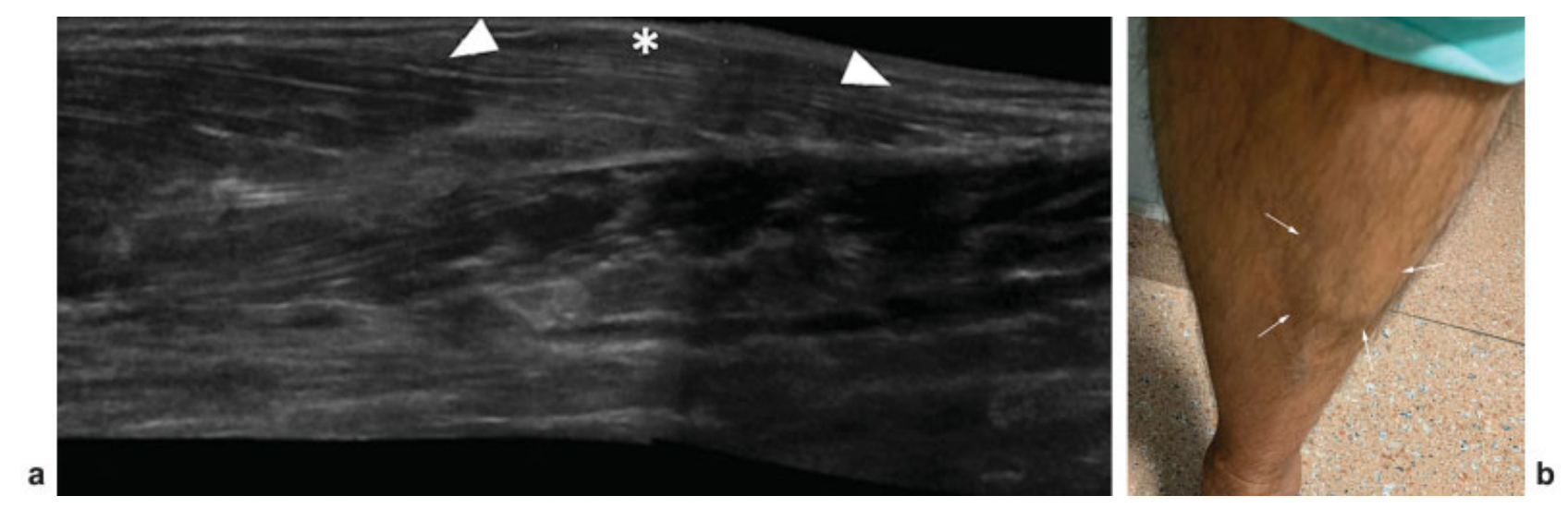

Fig. 9 Tibialis anterior muscle herniation. (a) Longitudinal US scan shows a defect in fascia covering tibialis anterior (arrowheads) with a focal bulge of muscle belly (asterisk). (b) Bulging at middle third of the anterolateral leg becoming evident during contraction.

cases of acute calcific tendinopathy, calcifications are fluid and not easily detected on shoulder radiograph. ${ }^{52}$ In these cases, US can be used effectively to detect the presence of a calcific deposit in one of the rotator cuff tendons or in the subacromial bursa. ${ }^{53}$ At the same time, US can be used to guide percutaneous irrigation of calcific tendinopathy to remove calcium and

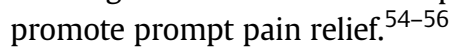

\section{Peripheral Nerve Injuries}

High-resolution US has emerged as a pivotal imaging modality in the evaluation of acute and chronic nerve conditions. Peripheral nerves normally present a fascicular "honeycomb" appearance due to the presence of multiple hypoechoic fascicles, each of which consists of numerous individual axons. ${ }^{57}$

Peripheral nerve injuries were classified by Seddon into three main types of fiber injury: neurapraxia, axonotmesis, and neurotmesis. ${ }^{58}$ Neurapraxia represents a stretch or compression injury with no axonal or connective tissue discontinuity; thus recovery is relatively fast, usually within 2 weeks to a few months, because the affected axons do not undergo Wallerian degeneration. In axonotmesis injury, varying degrees of axonal and internal connective tissue damage may be observed, characterized by full or partial integrity of the epineurium with potential regrowth and functional recovery. ${ }^{59}$ Neurotmesis is the most severe form of nerve injury where there is complete transection of all neural fibers with consequent loss of neural transmission..$^{59}$ In case of neurotmesis, US has proven useful in assaying the gap length between fibers and providing data for appropriate graft repair planning. However, distinguishing between neurotmesis and high-grade axonotmesis during the acute phase of nerve injury can be challenging in cases of smooth separated nerve ends or in the absence of neuroma. ${ }^{60}$ Similarly, before posttraumatic internal fiber distortion, differentiating between neurapraxia and low-grade axonotmetic injuries can also be difficult. ${ }^{15}$ Both neurapraxia and axonotmesis can show loss of the normal honeycomb fiber architecture and cross-sectional area increase. In fact, the use of a high-frequency US probe $(22-30 \mathrm{MHz})$ is mandatory in the differentiation between hypoechoic granulation tissue and scar formation in the nerve and nontransected fascicles. ${ }^{61}$

Zhu et $\mathrm{al}^{62}$ describe seven types of traumatic nerve injury based on US visualization of the nerve fascicle, perineurium, epineurium, and peripheral tissues with $93.2 \%$ accuracy in distinguishing grades of neural injury. In cases of fiber

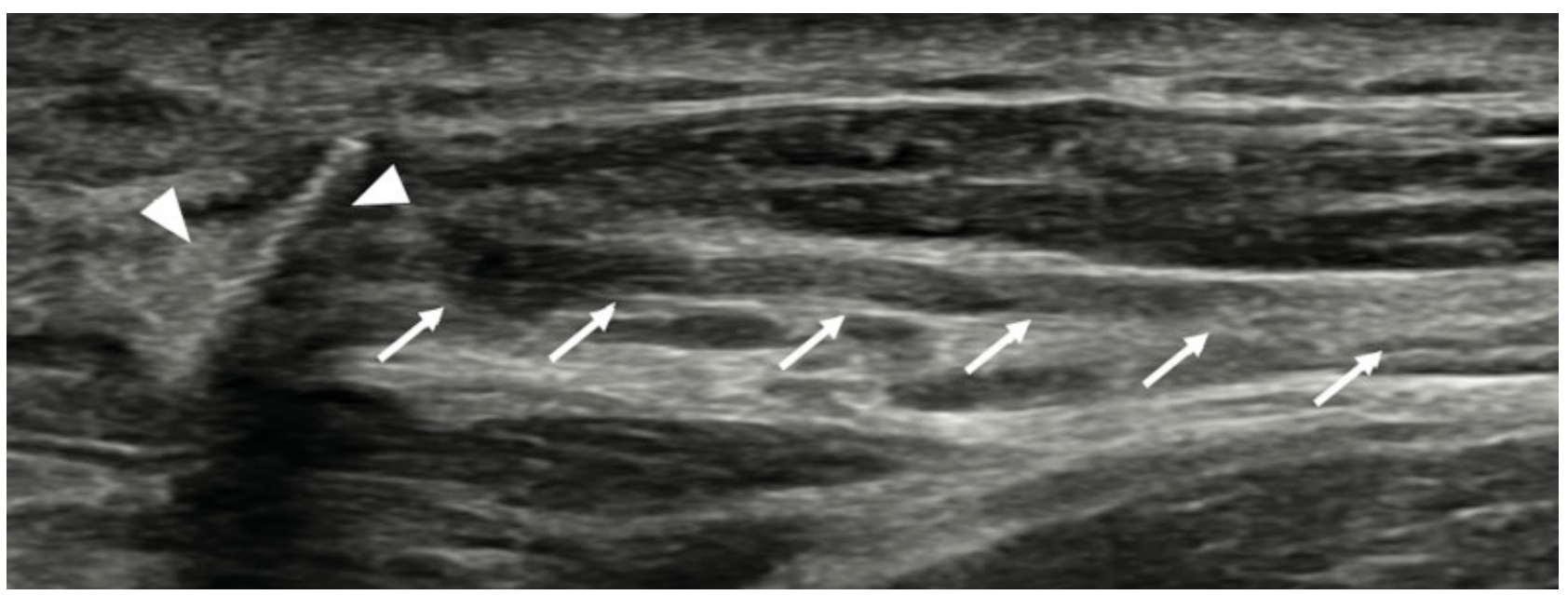

Fig. 10 Accessory spinal nerve (arrows) lesion with a visible hyperechoic foreign body (arrowhead). 
transection by a foreign body, US is reportedly able to localize the site of injury and possible foreign particles inside the nerve (-Fig. 10). Thus US is particularly advantageous in cases of metallic fragments that preclude magnetic resonance imaging evaluation. ${ }^{63,64}$

\section{Conclusion}

US has many benefits in the initial evaluation of a variety of MSK and ST lesions in the ED, not only as a diagnostic tool but also as guidance for interventional procedures. The radiologist can provide valuable data regarding the nature of a variety of pathologies, whether they be traumatic, inflammatory, or infectious, that will help the clinician or orthopaedic surgeon to devise the appropriate surgical or conservative treatment plan.

\section{Conflict of Interest}

None declared.

\section{References}

1 American College of Emergency Physicians. Emergency ultrasound guidelines. Ann Emerg Med 2009;53(04):550-570

2 O'Rourke K, Kibbee N, Stubbs A. Ultrasound for the evaluation of skin and soft tissue infections. Mo Med 2015;112(03):202-205

3 Talan DA, Krishnadasan A, Gorwitz RJ, et al; EMERGEncy ID Net Study Group. Comparison of Staphylococcus aureus from skin and soft-tissue infections in US emergency department patients, 2004 and 2008. Clin Infect Dis 2011;53(02):144-149

4 Pulia MS, Calderone MR, Meister JR, Santistevan J, May L. Update on management of skin and soft tissue infections in the emergency department. Curr Infect Dis Rep 2014;16(09):418

5 Chen KC, Lin ACM, Chong CF, Wang TL. An overview of point-ofcare ultrasound for soft tissue and musculoskeletal applications in the emergency department. J Intensive Care 2016;4:55

6 Chau CLF, Griffith JF. Musculoskeletal infections: ultrasound appearances. Clin Radiol 2005;60(02):149-159

7 Zacharias N, Velmahos GC, Salama A, et al. Diagnosis of necrotizing soft tissue infections by computed tomography. Arch Surg 2010;145(05):452-455

8 Umbert IJ, Winkelmann RK, Oliver GF, Peters MS. Necrotizing fasciitis: a clinical, microbiologic, and histopathologic study of 14 patients. J Am Acad Dermatol 1989;20(5 Pt 1):774-781

9 Hayeri MR, Ziai P, Shehata ML, Teytelboym OM, Huang BK. Softtissue infections and their imaging mimics: from cellulitis to necrotizing fasciitis. Radiographics 2016;36(06):1888-1910

$10 \mathrm{Wu}$ JS, Hochman MG. Soft-tissue tumors and tumorlike lesions: a systematic imaging approach. Radiology 2009;253(02):297-316

11 Aspelin P, Ekberg O, Thorsson O, Wilhelmsson M, Westlin N. Ultrasound examination of soft tissue injury of the lower limb in athletes. Am J Sports Med 1992;20(05):601-603

12 Di Pietto F, Chianca V, Zappia M, Romano S. Articular and periarticular hip lesions in soccer players. The importance of imaging in deciding which lesions will need surgery and which can be treated conservatively? Eur J Radiol 2018;105:227-238

13 Albano D, Chianca V, Tormenta S, Migliore A, Sconfienza LM. Old and new evidence concerning the crucial role of ultrasound in guiding intra-articular injections. Skeletal Radiol 2017;46(07):963-964

14 Sconfienza LM, Chianca V, Messina C, Albano D, Pozzi G, Bazzocchi A. Upper limb interventions. Radiol Clin North Am 2019;57(05): 1073-1082

15 Allen G, Obradov M, Chianca V, Messina C, Sconfienza LM. Ultrasound-guided musculoskeletal interventions for the most common hip and pelvis conditions: a step-by-step approach. Semin Musculoskelet Radiol 2019;23(03):e58-e67

16 Orlandi D, Corazza A, Arcidiacono A, et al. Ultrasound-guided procedures to treat sport-related muscle injuries. $\mathrm{Br} \mathrm{J}$ Radiol 2016;89(1057):20150484

17 Silvestri E, Barile A, Albano D, et al. Interventional therapeutic procedures in the musculoskeletal system: an Italian survey by the Italian College of Musculoskeletal Radiology. Radiol Med (Torino) 2018;123(04):314-321

18 Anderson MA, Newmeyer WL III, Kilgore ES Jr. Diagnosis and treatment of retained foreign bodies in the hand. Am J Surg 1982; 144(01):63-67

19 Bray PW, Mahoney JL, Campbell JP. Sensitivity and specificity of ultrasound in the diagnosis of foreign bodies in the hand. J Hand Surg Am 1995;20(04):661-666

20 Jacobson JA, Powell A, Craig JG, Bouffard JA, van Holsbeeck MT. Wooden foreign bodies in soft tissue: detection at US. Radiology 1998;206(01):45-48

21 Gilbert FJ, Campbell RS, Bayliss AP. The role of ultrasound in the detection of non-radiopaque foreign bodies. Clin Radiol 1990;41 (02):109-112

22 Blyme PJ, Lind T, Schantz K, Lavard P. Ultrasonographic detection of foreign bodies in soft tissue. A human cadaver study. Arch Orthop Trauma Surg 1990;110(01):24-25

23 Rubin JM, Adler RS, Bude RO, Fowlkes JB, Carson PL. Clean and dirty shadowing at US: a reappraisal. Radiology 1991;181(01): 231-236

24 Boyse TD, Fessell DP, Jacobson JA, Lin J, van Holsbeeck MT, Hayes CW. US of soft-tissue foreign bodies and associated complications with surgical correlation. Radiographics 2001;21(05):1251-1256

25 Waterbrook AL, Adhikari S, Stolz U, Adrion C. The accuracy of point-of-care ultrasound to diagnose long bone fractures in the ED. Am J Emerg Med 2013;31(09):1352-1356

26 Tessaro MO, McGovern TR, Dickman E, Haines LE. Point-of-care ultrasound detection of acute scaphoid fracture. Pediatr Emerg Care 2015;31(03):222-224

27 Platon A, Poletti P-A, Van Aaken J, et al. Occult fractures of the scaphoid: the role of ultrasonography in the emergency department. Skeletal Radiol 2011;40(07):869-875

28 Jain R, Jain N, Sheikh T, Yadav C. Early scaphoid fractures are better diagnosed with ultrasonography than X-rays: a prospective study over 114 patients. Chin J Traumatol 2018;21(04):206-210

29 Turk F, Kurt AB, Saglam S. Evaluation by ultrasound of traumatic rib fractures missed by radiography. Emerg Radiol 2010;17(06): 473-477

30 Pishbin E, Ahmadi K, Foogardi M, Salehi M, Seilanian Toosi F, Rahimi-Movaghar V. Comparison of ultrasonography and radiography in diagnosis of rib fractures. Chin J Traumatol 2017;20(04): 226-228

31 Dubrovsky AS, Kempinska A, Bank I, Mok E. Accuracy of ultrasonography for determining successful realignment of pediatric forearm fractures. Ann Emerg Med 2015;65(03):260-265

32 Wellsh BM, Kuzma JM. Ultrasound-guided pediatric forearm fracture reductions in a resource-limited ED. Am J Emerg Med 2016;34(01):40-44

33 Sconfienza LM, Albano D, Allen G, et al. Clinical indications for musculoskeletal ultrasound updated in 2017 by European Society of Musculoskeletal Radiology (ESSR) consensus. Eur Radiol 2018; 28(12):5338-5351

34 Klauser AS, Tagliafico A, Allen GM, et al. Clinical indications for musculoskeletal ultrasound: a Delphi-based consensus paper of the European Society of Musculoskeletal Radiology. Eur Radiol 2012;22(05):1140-1148

35 Phillips K, Costantino TG. Diagnosis of patellar tendon rupture by emergency ultrasound. J Emerg Med 2014;47(02):204-206

36 Oliva F, Bernardi G, De Luna V, et al. I.S.Mu.L.T. Achilles tendon ruptures guidelines. Muscles Ligaments Tendons J 2018; 8:310-363 
37 Mohammadrezaei N, Seyedhosseini J, Vahidi E. Validity of ultrasound in diagnosis of tendon injuries in penetrating extremity trauma. Am J Emerg Med 2017;35(07):945-948

38 Zappia M, Chianca V, Di Pietto F, et al. Imaging of long head biceps tendon. A multimodality pictorial essay. Acta Biomed 2019;90(5-S):84-94

39 Zappia M, Berritto D, Oliva F, et al. High resolution real time ultrasonography of the sural nerve after percutaneous repair of the Achilles tendon. Foot Ankle Surg 2017;37:636-643

40 Draghi F, Zacchino M, Canepari M, Nucci P, Alessandrino F. Muscle injuries: ultrasound evaluation in the acute phase. J Ultrasound 2013;16(04):209-214

41 Järvinen TAH, Järvinen TLN, Kääriäinen M, Kalimo H, Järvinen M. Muscle injuries: biology and treatment. Am J Sports Med 2005;33 (05):745-764

42 Guermazi A, Roemer FW, Robinson P, Tol JL, Regatte RR, Crema MD. Imaging of muscle injuries in sports medicine: sports imaging series. Radiology 2017;282(03):646-663

43 Chianca V, Albano D, Messina C, et al. Diffusion tensor imaging in the musculoskeletal and peripheral nerve systems: from experimental to clinical applications. Eur Radiol Exp 2017;1(01):12

44 Peetrons P. Ultrasound of muscles. Eur Radiol 2002;12(01):35-43

45 Lee JC, Mitchell AWM, Healy JC. Imaging of muscle injury in the elite athlete. Br J Radiol 2012;85(1016):1173-1185

46 Dönmez G, Evrenos MK, Cereb M, Karanfil Y, Doral MN. Double layer repair of tibialis anterior muscle hernia in a soccer player: a case report and review of the literature. Muscles Ligaments Tendons J 2016;5(04):331-334

47 Miniaci A, Rorabeck CH. Tibialis anterior muscle hernia: a rationale for treatment. Can J Surg 1987;30(02):79-80

48 Simonetti I, Chianca V, Zappia M, Carfora M, Jannelli E, Di Pietto F. A rare case of Hoffa's fat pad herniation in a young patient: dynamic ultrasound and MRI diagnosis. J Biol Regul Homeost Agents 2018;32(06, Suppl 1):77-81

49 Chianca V, Albano D, Messina C, et al. Rotator cuff calcific tendinopathy: from diagnosis to treatment. Acta Biomed 2018; 89(1-S):186-196

50 Sconfienza LM, Bandirali M, Serafini G, et al. Rotator cuff calcific tendinitis: does warm saline solution improve the short-term outcome of double-needle US-guided treatment? Radiology 2012;262(02):560-566

51 Sconfienza LM, Viganò S, Martini C, et al. Double-needle ultrasound-guided percutaneous treatment of rotator cuff calcific tendinitis: tips \& tricks. Skeletal Radiol 2013;42(01):19-24
52 Sconfienza LM, Randelli F, Sdao S, Sardanelli F, Randelli P. Septic bursitis after ultrasound-guided percutaneous treatment of rotator cuff calcific tendinopathy. PM R 2014;6(08):746-748

53 Orlandi D, Fabbro E, Mauri G, Savarino E, Serafini G, Sconfienza LMRE. RE: A Simple technique to restore needle patency during percutaneous lavage and aspiration of calcific rotator cuff tendinopathy. PM R 2013;5(07):633

54 Orlandi D, Mauri G, Lacelli F, et al. Rotator cuff calcific tendinopathy: randomized comparison of US-guided percutaneous treatments by using one or two needles. Radiology 2017;285(02):518-527

55 Lanza E, Banfi G, Serafini G, et al. Ultrasound-guided percutaneous irrigation in rotator cuff calcific tendinopathy: what is the evidence? A systematic review with proposals for future reporting. Eur Radiol 2015;25(07):2176-2183

56 Messina C, Banfi G, Orlandi D, et al. Ultrasound-guided interventional procedures around the shoulder. Br J Radiol 2016;89 (1057):20150372

57 Mallon S, Starcevic V, Rheinboldt M, Petraszko A. Sonographic evaluation of peripheral nerve pathology in the emergency setting. Emerg Radiol 2018;25(05):521-531

58 Seddon HJ. A classification of nerve injuries. BMJ 1942;2 (4260):237-239

59 Lauretti L, D’Alessandris QG, Granata G, et al. Ultrasound evaluation in traumatic peripheral nerve lesions: from diagnosis to surgical planning and follow-up. Acta Neurochir (Wien) 2015;157 (11):1947-1951; discussion 1951

60 Kara M, Özçakar L, De Muynck M, Tok F, Vanderstraeten G. Musculoskeletal ultrasound for peripheral nerve lesions. Eur J Phys Rehabil Med 2012;48(04):665-674; quiz 708

61 Toia F, Gagliardo A, D’Arpa S, Gagliardo C, Gagliardo G, Cordova A. Preoperative evaluation of peripheral nerve injuries: what is the place for ultrasound? J Neurosurg 2016;125(03):603-614

62 Zhu J, Liu F, Li D, Shao J, Hu B. Preliminary study of the types of traumatic peripheral nerve injuries by ultrasound. Eur Radiol 2011;21(05):1097-1101

63 Seddon HJ. A classification of nerve injuries. BMJ 1942;2 (4260):237-239

64 Sconfienza LM, Adriaensen M, Albano D, et al; Ultrasound and Interventional Subcommittees of the European Society of Musculoskeletal Radiology (ESSR). Clinical indications for image guided interventional procedures in the musculoskeletal system: a Delphi-based consensus paper from the European Society of Musculoskeletal Radiology (ESSR)-part III, nerves of the upper limb. Eur Radiol 2019; November 11 (Epub ahead of print) 